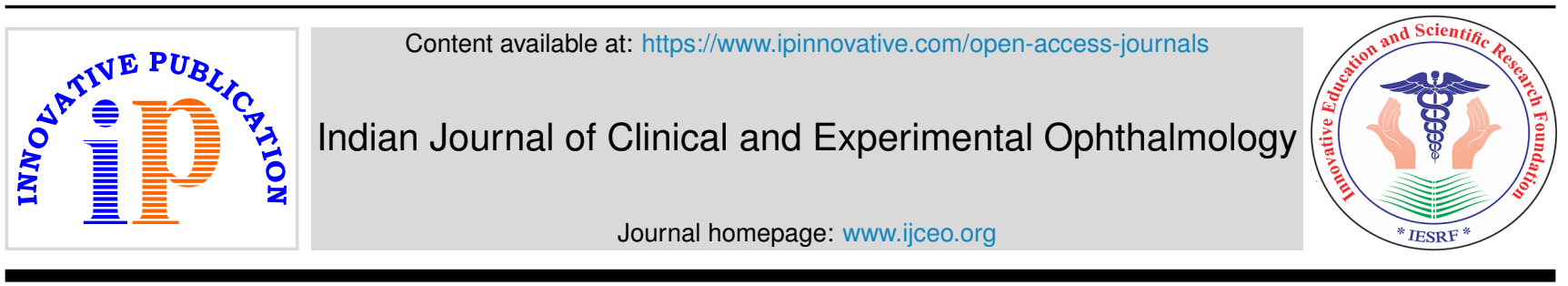

Original Research Article

\title{
Management of macular edema secondary to branch retinal vein occlusion-combined treatment with intravitreal bevacizumab and ozurdex implant
}

\author{
Anand Babu M N¹, Prashanth $\mathrm{C} \mathrm{N}^{1, *}$, Sribhargava Natesh ${ }^{2}$ \\ ${ }^{1}$ Dept. of Ophthalmology, Dr. B R Ambedkar Medical College, Bangalore, Karnataka, India \\ ${ }^{2}$ Nethra Eye Hospital, Bangalore, Karnataka, India
}

\section{A R T I C L E I N F O}

\section{Article history:}

Received 28-05-2020

Accepted 04-06-2020

Available online 01-04-2021

\section{Keywords:}

Macular edema secondary

Intravitreal bevacizumab

Intravitreal Ozurdex

\begin{abstract}
A B S T R A C T
Purpose: To evaluate the efficacy and safety of a dexamethasone implant in combination with intravitreal bevacizumab injection in the management of macular edema secondary to branch retinal venous occlusion. Materials and Methods: 10 eyes were prospectively investigated. Each eye was treated with intravitreal bevacizumab followed by intravitreal ozurdex at a two-week interval. Recurrence of macular edema was treated with ozurdex only. Patient were evaluated preoperatively with BCVA, IOP, OCT and fundus evaluation and followed up at 15 days, 2 months and 4 months of ozurdex injection. Fallow up all patient for 1 year duration.

Results: Mean BCVA at presentation was $0.81 \log$ mar, and that improved to after 15 days of intravitreal bevacizumab was $0.55 \log$ mar. At 15 days, 2 months and 4 months of intravitreal ozurdex implantation mean BCVA was 0.54logmar, $0.54 \log$ mar and 0.6logmar respectively. Mean central foveal retinal thickness at presentation was $538 \mu \mathrm{m}$ and reduced to $235 \mu \mathrm{m}$, after intravitreal bevacizumab. At 15 days, 2 months and 4 months after intravitreal ozurdex implantation mean central foveal retinal thickness was $182.14 \mu \mathrm{m}, 189.28 \mu \mathrm{m}$ and $352.14 \mu \mathrm{m}$ respectively. Mean Intraocular pressure (IOP) was elevated about 1 $\mathrm{mm}$ of $\mathrm{Hg}$ after bevacizumab, about $3 \mathrm{~mm}$ of $\mathrm{Hg}$ after 4 months of ozurdex with using single anti glaucoma medication and one patient had progression of cataract after $2^{\text {nd }}$ injection of ozurdex.

Conclusion: Combined treatment of intravitreal bevacizumab and ozurdex shows better and a sustained functional outcome. Increased intraocular pressure and cataract formation can be potential concerns and should be monitored.

(C) This is an open access article distributed under the terms of the Creative Commons Attribution License (https://creativecommons.org/licenses/by/4.0/) which permits unrestricted use, distribution, and reproduction in any medium, provided the original author and source are credited.
\end{abstract}

\section{Introduction}

Retinal vein occlusion (RVO) is a common vascular disorder of the retina second to diabetic retinopathy. Branched retinal vein occlusion (BRVO) is a most common form of retinal vein occlusion. Macular edema is a main cause for visual loss in BRVO. Other causes of visual decrease in BRVO is retinal or optic disc neovascularization and neovascular glaucoma.

The pathogenesis of macular edema in RVO have been identified to be due to factors such as the hydrostatic effects from increased venous pressure, the

\footnotetext{
* Corresponding author.

E-mail address: dr.babuanand@gmail.com (Prashanth C N).
}

presence of inflammatory cytokines (e.g., prostaglandins and interleukin-6), and the up regulation of endothelial tight junction proteins, ${ }^{1}$ and /or increased vascular endothelial growth factor (VEGF) expression. ${ }^{2}$ Common risk factors for RVO include arterial hypertension, hypercholesterolemia, diabetes mellitus, and glaucoma. ${ }^{3}$

Optical coherence tomography (OCT) is an important tool in the diagnosis of macular edema (ME).

Grid laser photocoagulation was shown to be benefit for treating ME in the branch vein occlusion study (BVOS) with limited in visual improvement. ${ }^{4}$

Anti-vascular endothelial growth factor (anti-VEGF) introduction has revolutionised the management of $\mathrm{ME}$ secondary to RVO provide short term visual benefit. 
Recurrent I is commonly encountered problem with intravitreal monotherapy, leading to the need of multiple injection. Few patients seems to develop resistant ME and can even develop increased or rebound ME after anti-VEGF therapy. ${ }^{5-7}$ Since the intravitreal dexamethasone implant (Ozurdex; Allergan, Irvine, CA) was recently approved for $\mathrm{RVO},{ }^{8}$ we used this treatment as combination with antiVEGF.

We aim to study the combination therapy in our study.

\section{Materials and Methods}

Our study is prospective, consecutive, non-randomized case series, 10 eyes of 9 patients with BRVO with ME, 6 males and 3 females (mean age 59.28 years) with maximum duration of symptoms of 4 months were included. 6 eyes presented with superior temporal quadrant BRVO and 4 eyes presented with inferior temporal quadrant BRVO. We excluded patients with a known history of glaucoma or steroid response, as well as history of vitrectomy and neovascularization in the anterior or posterior segment.

Informed consent was procured prior to recruitment in a consecutive manner. Each patient underwent detail eye examination include best corrected visual acuity (BCVA), anterior segment examination, intraocular pressure (IOP) and fundus examination. OCT (Spectral domain - primus Zeiss) scan was done each visit. Each patient received intravitreal bevacizumab at presentation and after 15 days intravitreal ozurdex was given. Central foveal thickness (CFT) and parafoveal thickness (PFT) was measured at the initiation of treatment, at 15 days, 2 months and 4 months after intravitreal Ozurdex implant. Second injection was considered for patients with recurrent edema at four months. Each patient fallow up done for period of 1 year as shown in the Table 1.

\section{Results}

A total of 10 eyes of 9 patients ( 8 unilateral, 1bilateral were recruited.

The mean IOP at presentation was $14.71 \mathrm{~mm}$ of $\mathrm{Hg}$, at two weeks of intravitreal bevacizumab was $15 \mathrm{~mm}$ of $\mathrm{Hg}$. At 15 days, 2 months and 4 months of intravitreal ozurdex mean IOP was $17 \mathrm{~mm}$ of $\mathrm{Hg}, 16.42 \mathrm{~mm}$ of $\mathrm{Hg}$ and $16.28 \mathrm{~mm}$ of $\mathrm{Hg}$ with one ant glaucoma medication (Dorzolamide eye drops).

At presentation, mean BCVA was $0.81 \log$ mar, after 15 days of intravitreal bevacizumab was $0.55 \log$ mar, after 15 days, 2 months and 4 months of intravitreal ozurdex was $0.54 \log m a r, 0.54 \log$ mar and 0.6logmar respectively.

MeanCFT at presentation was $538 \mu \mathrm{m}$ and reduced to $235 \mu \mathrm{m}$, after intravitreal bevacizumab. At 15 days, 2 months and 4 months after intravitreal ozurdex implantation mean CFT was $182.14 \mu \mathrm{m}, 189.28 \mu \mathrm{m}$ and $352.14 \mu \mathrm{m}$ respectively.

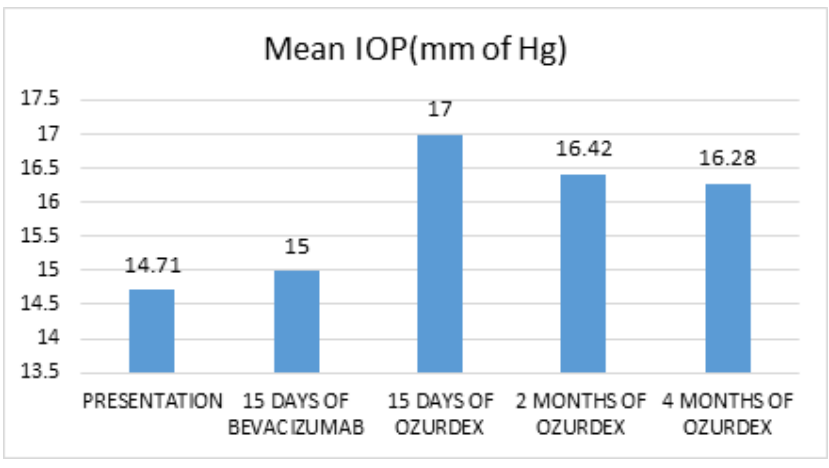

Fig. 1:

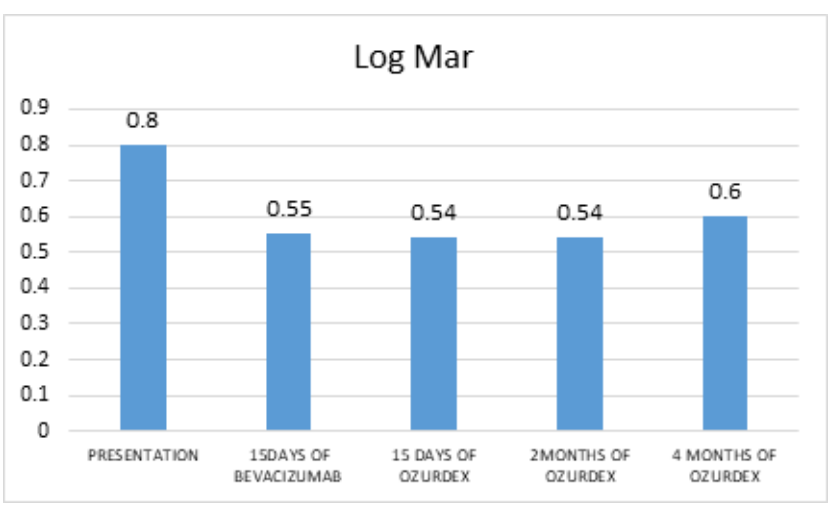

Fig. 2:

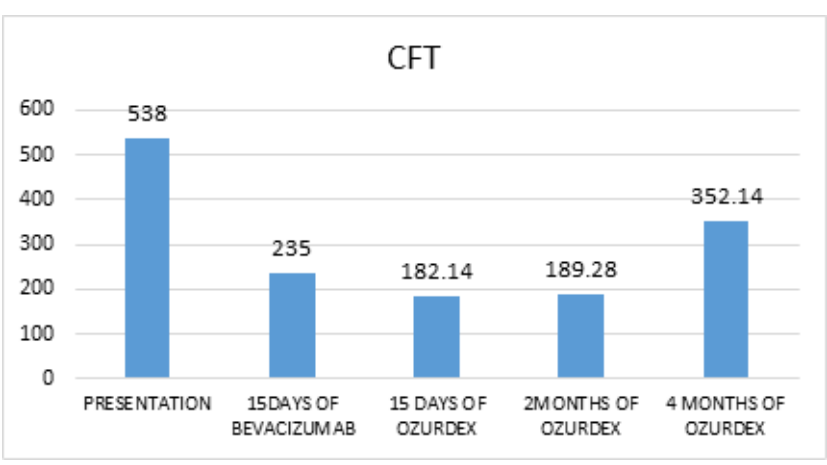

Fig. 3:

MeanPFT at presentation was $610 \mu \mathrm{m}$, after 15 days of intravitreal bevacizumab meanpara foveal retinal thickness was $353.57 \mu \mathrm{m}$. At 15 days, 2 months and 4 months of intravitreal ozurdex mean PFT was $258.57 \mu \mathrm{m}, 262.85 \mu \mathrm{m}$ and $372.14 \mu \mathrm{m}$ respectively.

$4 / 10(40 \%)$ of eyes presented with recurrence of ME at four months. Each patient received second dose of intravitreal Ozurdex. Fallow up done. Mean CFT reduced from $420 \mu \mathrm{m}$ to $210 \mu \mathrm{m}$ at 2 months, $325 \mu \mathrm{m}$ at 4 months. Out of 4 case 1 case had recurrent ME and received $3^{r d}$ dose of intravitreal ozurdex. 
Table 1:

\begin{tabular}{|c|c|c|c|c|c|}
\hline Presentation & 15 days & 2 months & 4 months & 8 months & 12 months \\
\hline $\begin{array}{l}\text { Clinical } \\
\text { evaluation+Bevacizumab }\end{array}$ & Ozurdex & & $\begin{array}{l}\text { Recurrent } \\
\text {-Ozurdex }\end{array}$ & & \\
\hline
\end{tabular}

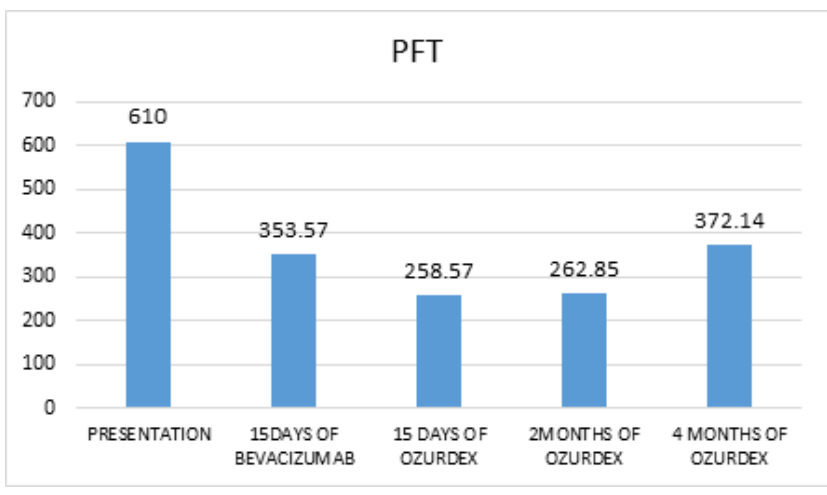

Fig. 4:

Out of 10 eyes 6 cases were pseudophakia, out of 4 phakic eyes 1 eye developed cataract after $2^{\text {nd }}$ Injection of ozurdex.

Number of visit to the hospital was 6 in one year duration. Out of 10 eyes, 6 eyes had received only 2 intravitreal injection (Bevacizumab +Ozurdex), 3 eyes received 3 intravitreal injection (Bevacizumab +2 dose of Ozurdex) and 1 eye received 4 intravitreal injection (Bevacizumab +3 dose of Ozurdex).

\section{Case 1}

A female patient aged 58 years presents with reduced vision in Right eye(RE), her vision in RE was 6/36, fundus picture shows multiple superficial haemorrhage in superior temporal quadrant with few cotton wool spots and hard exudates and OCT shows cystoid macular edema (CME) with IS/OS junction disruption (Figure 5 a). After 15 days of intravitreal bevacizumab her Vision improved to 6/18. After ozurdex injection her vision improved to $6 / 12$, fundus shows resolving superficial haemorrhage with few cotton wool spots (Figure 5b). After 4 months her BCVA was 6/9, fundus shows resolved superficial haemorrhage in superior temporal quadrant and OCT shows normal foveal contour with resolved ME. (Figure $5 \mathrm{c}$ ).

\section{Case 2}

A male patient aged 62 years presents with reduced vision in RE, BCVA was 6/60, fundus shows multiple superficial haemorrhage in inferior temporal quadrant and OCT shows CME (Figure 6 a). After 15 days of intravitreal bevacizumab his BCVA improved to 6/24, OCT scan shows CME with subretinal fluid (Figure 6 b). After Ozurdex injection his
Vision improved to 6/18, OCT scan shows reduced ME with few parafoveal few cystic changes (Figure $6 \mathrm{c}$ ). After 4 months of ozurdex vision worsened to $6 / 36$ and OCT scan show multiple cystoid changes with epiretinal membrane (Figure $6 \mathrm{~d}$ ). He received $2^{\text {nd }}$ dose of intravitreal Ozurdex, his BCVA improved to $6 / 18$ and oct scan shows complete resolution of macular edema (Figure 6 e).

\section{Discussion}

Presently macular edema due to BRVOis treated with three pharmacological drugs including anti-VEGF such as bevacizumab (Off label use) or ranibizumab, aflibrecept and a corticosteroid dexamethasone implant that is ozurdex.

In clinical trial, anti-VEGF such as ranibizumab revealed a beneficial effect on visual function and reduction in central macular thickness in eye with BRVO and diabetic macular edema. ${ }^{9}$ However, with respect to shorter halflife of ranbizumab, ${ }^{10,11}$ numerous injections required to achieve and maintains the therapeutic effect. This is also valid for bevacizumab as shown by Epstein et al., ${ }^{12}$ who performed injection every 6 weeks for 12 months with significant improvement of visual acuity and reduction of ME. Frequent intravitreal injection require frequent visits to the hospital and also risk of side effects and complications. Since the intravitreal dexamethasone implant (Ozurdex; Allergan, Irvine, CA) was recently approved for $\mathrm{RVO},{ }^{8}$ we used this treatment as combination with anti-VEGF. Which results in maintain $\mathrm{ME}$ with reduced number of injections and also reduced the number of patient visits. We aimed to evaluate the effect of combination of therapy in case ME due to BRVO. Initial intravitreal bevacizumab helps in reduction of ME. Ozurdex helps to maintain reduction in $\mathrm{ME}$ for longer duration. Combination therapy helps in reduced number of patient visit for procedures and monitoring visits and hence reduced cost of monotherapy.

In our case series BCVA improved and I decreased significantly after intravitreal bevacizumab later both parameters improved and maintained with use of intravitreal ozurdex. After 4 months $40 \%$ of cases were showed recurrence, treated with repeat intravitreal ozurdex. Out of 4 recurrent cases only one case needed $3^{r d}$ dose of intravitreal ozurdex.

We hypothesized that treatment with anti-VEGF will have an early impact and following the ozurdex implantation the effect is sustained. However the time interval for recurrence could not be prolonged, which is in contract to recent study of Singer et al., ${ }^{13}$ Recurrence occurs after period of 3.2 and 3.8months and were in line with the known 

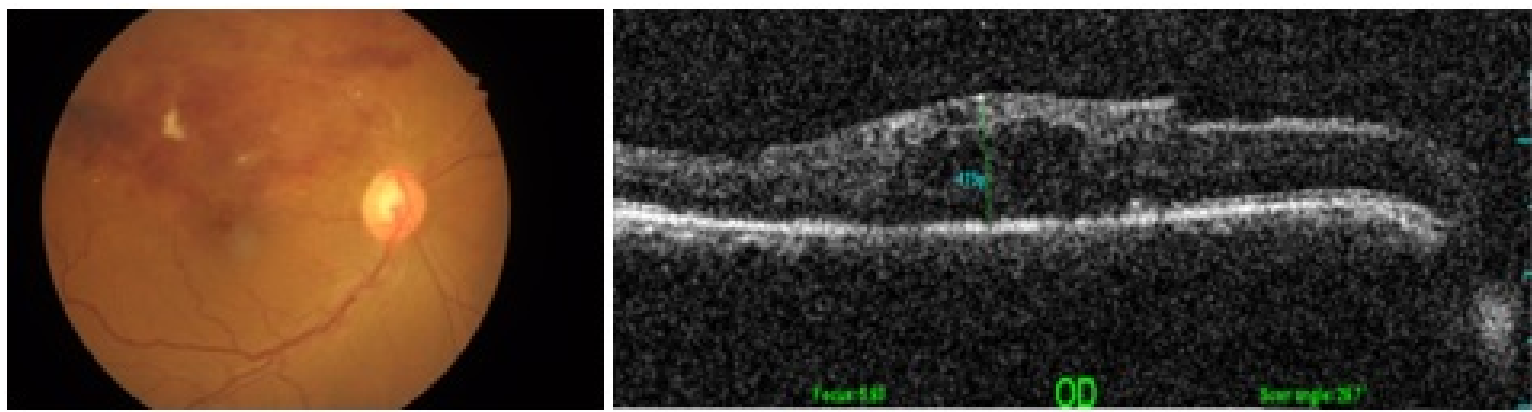

a

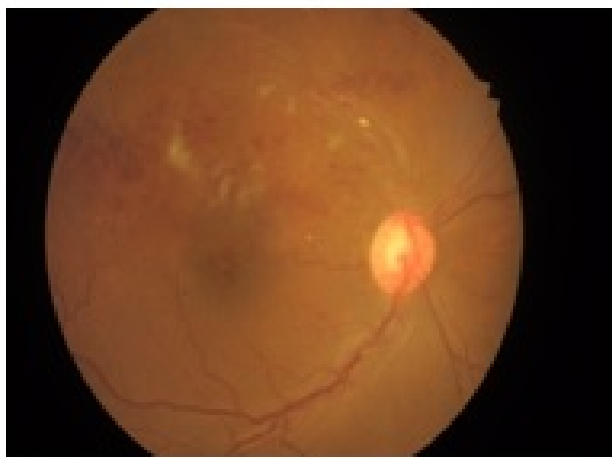

b
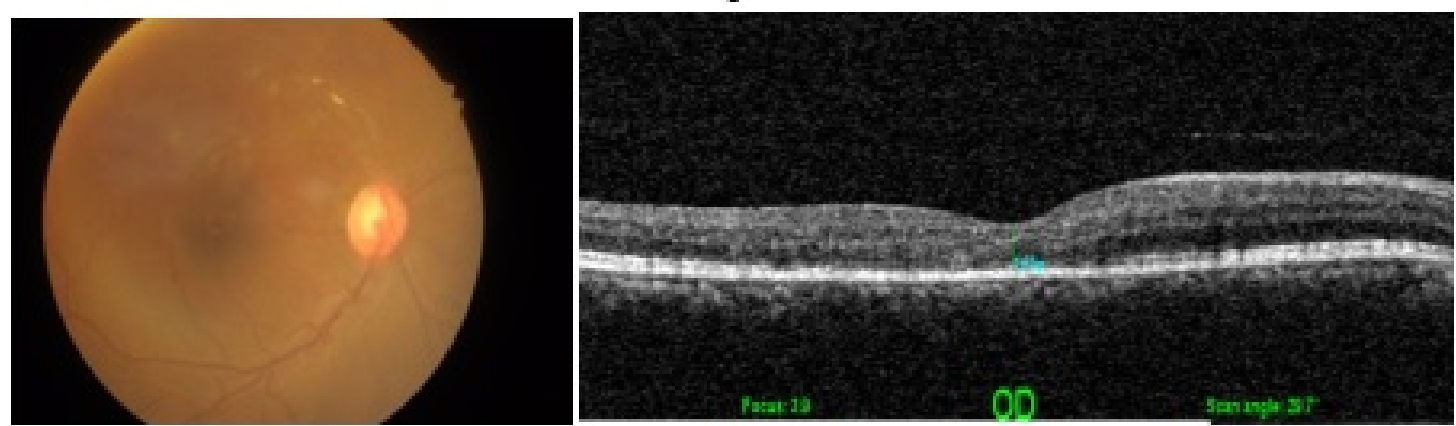

C

Fig. 5: a: Fundus picture shows multiple superficial haemorrhage in superior temporal quadrant with few cotton wool spots and hard exudates and OCT shows cystoid macular edema (CME) with IS/OS junction disruption; b: Fundus picture shows with few cotton wool spots and reduced superficial haemorrhage; c: Fundus shows resolving superficial haemorrhage resolved superficial haemorrhage in superior temporal quadrant and OCT shows normal foveal contour with resolved ME

pharmacokinetics of the ozurdex implant and the results of Geneva trial, which revealed a decrease of treatment effect at about 3-4 months after implantation. ${ }^{14}$

Mayer et al., ${ }^{15}$ studied efficacy and safety of dexamethasone implant alone or in combination with bevacizumab. 16 patients of BRVO were treated with intravitreal ozurdex and 12 patients with 3 consecutive bevacizumab injections fallowed by intravitreal ozurdex. Results noticed BCVA improved by $7.8( \pm 2.9)$ letter with ozurdex and $9.4( \pm 2.1)$ letters in combination group. In our series we used single injection of Bevacizumab with significant of improvement of vision. There is a benefit of combining the two agents for greater visual outcome.
Mayer et al., ${ }^{15}$ observed an elevation of $>5 \mathrm{~mm}$ of $\mathrm{Hg}$ compared with the baseline in approximately $40 \%$ of patients, irrespective of treatment regimen. Whereas in our case series we are using single dose anti glaucoma drug (Dorzolamide eye drops) and noticed IOP rise of $3 \mathrm{~mm}$ of $\mathrm{Hg}$ with baseline at the end of 4 months. Although we had no uncontrolled rise of IOP based on our experience in this case series. We suggest exclude patient with known history of glaucoma and steroid response to the treatment. Dorzolamide is a topical carbonic inhibitor used to reduce IOP and CME. Reduction of ME is by supressing production of proinflammatory cytokines, interleukin- $6 .{ }^{16}$ However, response is better in retinal pigmentary epithelial disease than in RVO. ${ }^{17}$ 


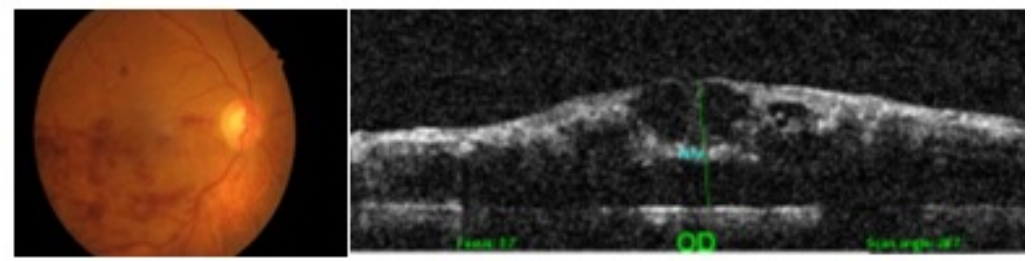

a

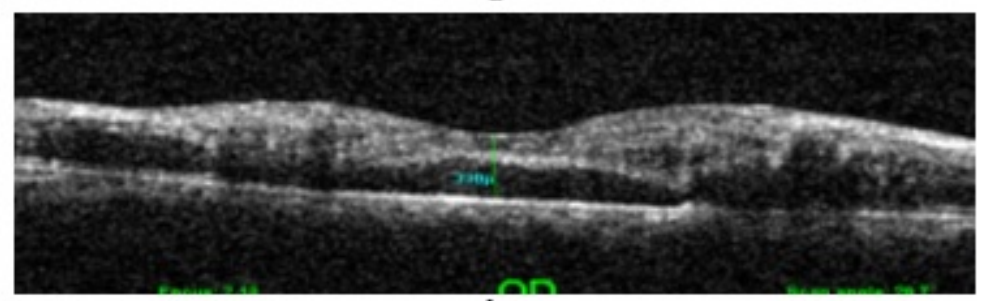

b

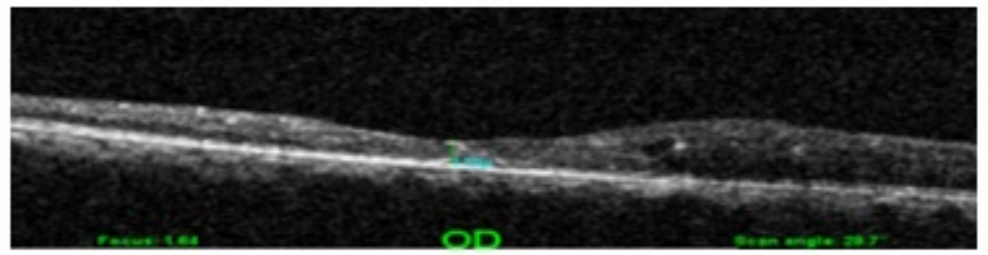

c

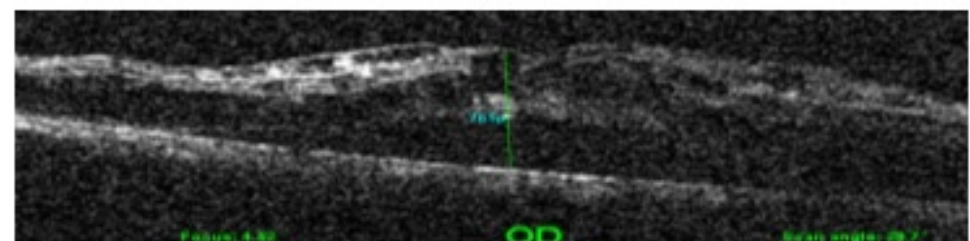

d

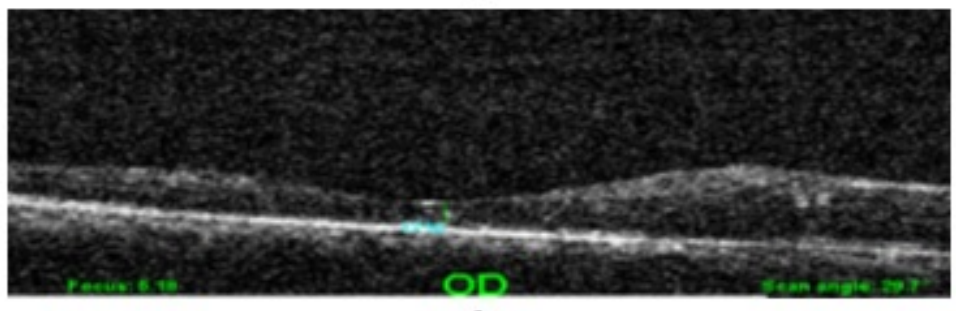

e

Fig. 6: a: Fundus shows multiple superficial haemorrhage in inferior temporal quadrant and OCT shows CME; b: OCT scan shows CME with subretinal fluid; c: OCT scan shows reduced ME with few parafoveal cystic changes; d: OCT scan show multiple cystoid changes with epiretinal membrane; e: OCT scan shows complete resolution of macular edema

Michael A Singer ${ }^{13}$ et al., study showed mean changes in OCT measured retinal thickness decreased by $195 \mu \mathrm{m}$ at 2 weeks after intravitreal bevacizumab, with additional 63 $\mu \mathrm{m}$ decrease seen at 4 and 6 weeks, with additional $40 \mu \mathrm{m}$ decrease seen at 2 months and at 4 months $124 \mu$ m increase in macular thickness after Ozurdex compare to baseline. The mean BCVA increased from 9.4 to 12.9 letters at 4weeks, 12.3 letters at 2 months and back to 10 letters at 4 months.

In our case series also central retinal thickness decreased by $303 \mu \mathrm{m}$ at 2 weeks after intravitreal bevacizumab, with additional $53 \mu \mathrm{m}$ at 4 weeks, $46 \mu \mathrm{m}$ at 2 months and $117.14 \mu \mathrm{m}$ increase at 4 months in macular thickness after ozurdex compared to baseline. We can expect a possible recurrence of edema at 4 months for most patients and review. Combination therapy showed that improvement in BCVA and macular thickness is sustained for four months and also increases the percentage of patients whose macula was essential fluid free compared with anti VEGF therapy alone.

In our case series number of visit to the hospital was 6 in one year duration and also needed a less number of injection. Whereas in monotherapy the number of visit would be about 10 and require multiple dose of intravitreal injection as in Seong Joon Ahn et al. ${ }^{18}$ study initial dose of 
three monthly intravitreal injection versus PRN intravitreal injection of bevacizumab for macular edema secondary to BRVO showed mean number of injection over the 1 year period were $3.8 \pm 1$ (range, $3-7$ ) in the 3 monthly initial dose group and $2.3 \pm 1.3$ (range, $1-6$ ) in the PRN group. Study visit also more.

Combined treatment of intravitreal bevacizumab and ozurdex shows better and a sustained functional outcome. Also reduced the number of visit and reduced the cost compare monotherapy.

\section{Source of Funding}

None.

\section{Conflict of Interest}

None.

\section{References}

1. Antonetti DA, Barber AJ, Khin S, Lieth E, Tarbell JM, Gardner TW. Vascular permeability in experimental diabetes is associated with reduced endothelial occludin content: vascular endothelial growth factor decreases occludin in retinal endothelial cells. Penn State Retina Research Group. Diabetes. 1998;47(12):1953-9. 1010102337/diahetes 47/21053.

2. Campochiaro PA, Hafiz G, Shah SM, Nguyen QD, Do YH Ranizumab for macular edema: due to retinal vein occlusion: implication of VEGF as acritical stimulator. Mol Ther. 2008;16(4):791-9.

3. Shahsuvaryan ML, Melkonyan AK. Central Retinal Vein Occlusion Risk Profile: A Case-Control Study. Eur J Ophthalmol. 2003;13(5):445-52. 100:10 1777/20672103013005051.

4. Argon laser photocoagulation for macular edema in branch vein occlusion. The Branch vein occlusion study group. Am J Ophthalmol. 1984;98(3):271-82.

5. Gallemore RP. NSAIDs in treatment of retinal disorders. Rev Ophthalmol. 2006;13:11

6. Matsumoto Y, Freund KB, Peiretti E, Cooney MJ, Ferrara D, Yannuzzi LA, et al. Rebound macular edema following bevacizumab (Avastin) therapy for retinal venous occlusive disease. Retina. 2007;27(4):426-

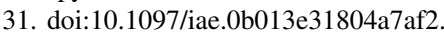

7. Yasuda S, Kondo M, Kachi S, Ito Y, Terui T, Ueno S, et al. Rebound of macular edema after intravitreal bevacizumab therapy in eyes with macular edema secondary to branch retinal vein occlusion. Retina.

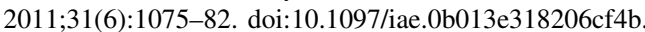

8. Chang-Lin J, Attar M, Acheampong AA, Robinson MR, Whitcup SM, Kuppermann BD, et al. Pharmacokinetics and Pharmacodynamics of a Sustained-Release Dexamethasone Intravitreal Implant. Invest Opthalmol Vis Sci. 2011;52(1):80. 10010

9. Brown DM, Campochiaro PA, Bhisitkul RB, Ho AC, Gray S, Saroj $\mathrm{N}$, et al. Sustained Benefits from Ranibizumab for Macular Edema
Following Branch Retinal Vein Occlusion: 12-Month Outcomes of a Phase III Study. Ophthalmology. 2011;118:1594-1602. doi:10.1016/1.ophtha.2011.02.022

10. Bakri SJ, Snyder MR, Reid JM, Pulido JS, Ezzat MK, Singh RJ. Pharmacokinetics of Intravitreal Ranibizumab (Lucentis). Ophthalmology. 2007;114:2179-82. do1:10.1016/1.0phtha.2007.09.012

11. Gupta SK, Yadav I, Deshmukh S, Maurya RP, Singh VP. Predictors of visual response to Intravitreal Bevacizumab for treatment of Diabetic Macular Edema. Ind J Clin Exp Ophthalmol. 2015;1(1):35-40.

12. Epstein DL, Algvere PV, von Wendt G, Seregard S, Kvanta A. Benefit from Bevacizumab for Macular Edema in Central Retinal Vein Occlusion: Twelve-Month Results of a Prospective, Randomized Study. Ophthalmology. 2012;119:2587-91. doi:10.1016/j.ophtha.2012.06.037

13. Singer MA, Bell DJ, Woods P, Pollard J, Boord T, Herro A Effect of combinatopn therapy with bevacizumab and dexamethasone intravitreal implant in patients with retinal vein occlusion. Retina. 2012;32(7):1289-94

14. Haller JA, Bandello F, Belfort R, Blumenkranz MS, Gillies M, Heier J, et al. Randomized, Sham-Controlled Trial of Dexamethasone Intravitreal Implant in Patients with Macular Edema Due to Retinal Vein Occlusion. Ophthalmology. 2010;117(6):1134-46. doi:10.1016/1.0phtha.2010.03.032

15. Mayer WJ, Wolf A, Kernt M, Kook D, Kampik A, Ulbig M, et al. Twelve-month experience with Ozurdex for the treatment of macular edema associated with retinal vein occlusion. Eye. 2013;27(7):81622. do1:10.1038/eye.2013.19.

16. Kawai K, Ohashi H, Suzuki T, Kitagaki H, Fujisawa S. Effect of antiglaucoma drugs on inflammatory cytokine production by human and murine peripheral blood mononuclear cells. Nippon Ganka Gakkai Zasshi. 2010;114:669-77.

17. Wolfensberger TJ. The role of carbonic anhydrase inhibitors in the management of macular edema. Doc Ophthalmol. 1999;97:387-97.

18. Ahn SJ, Ahn J, Woo SJ, Park KH. Initial dose of three monthly intravitreal injections versus PRN intravitreal injections of bevacizumab for macular edema secondary to branch retinal vein occlusion. Biomed Res Int. 2013;2013:209735. doi:10. $155 / 2013 / 209735$.

\section{Author biography}

Anand Babu M N, Assistant Professor

Prashanth C N, Associate Professor

Sribhargava Natesh, Associate Professor

Cite this article: Babu M N A, Prashanth C N, Natesh S. Management of macular edema secondary to branch retinal vein occlusion-combined treatment with intravitreal bevacizumab and ozurdex implant. Indian J Clin Exp Ophthalmol 2021;7(1):240-245. 